\title{
Experience Affects Critical Period Plasticity in the Visual Cortex through an Epigenetic Regulation of Histone Post- Translational Modifications
}

\author{
Laura Baroncelli, ${ }^{1 \star}$ Manuela Scali, ${ }^{1 \star}$ Gabriele Sansevero, ${ }^{1,2 \star}$ Francesco Olimpico, ${ }^{1}$ Ilaria Manno, ${ }^{3}$ Mario Costa, ${ }^{1,3}$ \\ and Alessandro Sale ${ }^{1}$ \\ ${ }^{1}$ Neuroscience Institute, National Research Council, I-56124 Pisa, Italy, ${ }^{2}$ NEUROFARBA, University of Florence, Florence, Italy, and ${ }^{3}$ Scuola Normale \\ Superiore, I-56126 Pisa, Italy
}

During an early phase of enhanced sensitivity called the critical period (CP), monocular deprivation causes a shift in the response of visual cortex binocular neurons in favor of the nondeprived eye, a process named ocular dominance (OD) plasticity. While the time course of the CP for OD plasticity can be modulated by genetic/pharmacological interventions targeting GABAergic inhibition, whether an increased sensory-motor experience can affect this major plastic phenomenon is not known. We report that exposure to environmental enrichment (EE) accelerated the closure of the $\mathrm{CP}$ for $\mathrm{OD}$ plasticity in the rat visual cortex. Histone $\mathrm{H} 3$ acetylation was developmentally regulated in primary visual cortex, with enhanced levels being detectable early in enriched pups, and chromatin immunoprecipitation revealed an increase at the level of the BDNF P3 promoter. Administration of the histone deacetylase inhibitor SAHA (suberoylanilide hydroxamic acid) to animals reared in a standard cage mimicked the increase in $\mathrm{H} 3$ acetylation observed in the visual cortex and resulted in an accelerated decay of OD plasticity. Finally, exposure to EE in adulthood upregulated H3 acetylation and was paralleled by a reopening of the CP. These findings demonstrate a critical involvement of the epigenetic machinery as a mediator of visual cortex developmental plasticity and of the impact of EE on OD plasticity.

Key words: BDNF; critical period; histone acetylation; ocular dominance plasticity

\section{Significance Statement}

While it is known that an epigenetic remodeling of chromatin structure controls developmental plasticity in the visual cortex, three main questions have remained open. Which is the physiological time course of histone modifications? Is it possible, by manipulating the chromatin epigenetic state, to modulate plasticity levels during the critical period? How can we regulate histone acetylation in the adult brain in a noninvasive manner? We show that the early exposure of rat pups to enriching environmental conditions accelerates the critical period for plasticity in the primary visual cortex, linking this effect to increased histone acetylation, specifically at the BDNF gene level. Moreover, we report that the exposure of adult animals to environmental enrichment enhances histone acetylation and reopens juvenile-like plasticity.

\section{Introduction}

Experience sculpts brain connectivity during restricted developmental time windows called critical periods (CPs; Berardi et al., 2000). The most common approach to assessing experience-

\footnotetext{
Received May 8, 2015; revised Dec. 15, 2015; accepted Jan. 5, 2016.

Author contributions: L.B. and A.S. designed research; L.B., M.S., G.S., F.O., I.M., M.C., and A.S. performed research; A.S. contributed unpublished reagents/analytic tools; L.B., G.S., F.O., M.C., and A.S. analyzed data; A.S. wrote the paper.

We thank Professor Lamberto Maffei for his support and advice on the preparation of the manuscript.

*L.B., M.S., and G.S. contributed equally to this work.

The authors declare no competing financial interests.

Correspondence should be addressed to Alessandro Sale, CNR (National Research Council), Neuroscience Institute, Pisa, Via Moruzzi 1, I-56124 Pisa, Italy. E-mail: sale@in.cnr.it.

DOI:10.1523/JNEUROSCI.1787-15.2016

Copyright $\odot 2016$ the authors $\quad 0270-6474 / 16 / 363430-11 \$ 15.00 / 0$
}

dependent plasticity in the developing brain has long been to deprive a subject of experience in one sensory modality and to investigate the ensuing effects on sensory development. In the visual system, the classic experiments by Wiesel and Hubel (1963) first demonstrated in kittens that depriving one eye of vision [monocular deprivation (MD)] causes a dramatic reduction in the proportion of cortical neurons driven by the deprived eye, a process called ocular dominance (OD) plasticity (Gordon and Stryker, 1996). Subsequent studies demonstrated that OD plasticity is widespread in mammals with binocular vision, is maximal during the $\mathrm{CP}$, and then progressively declines, with a time course different in different species (Wiesel and Hubel, 1963; Dews and Wiesel, 1970; Hubel and Wiesel, 1970a,b; Blakemore et al., 1978; Giffin and Mitchell, 1978; Fagiolini et al., 1994; Gordon and Stryker, 1996; Fagiolini and Hensch, 2000). 
A large body of research in this field has been focused on uncovering key molecular players acting as brakes that limit the potential for plastic changes in the adult brain. These factors include maturation of intracortical GABAergic interneurons, development of chondroitin sulfate proteoglycans surrounding neuronal cell bodies in structures called perineuronal nets, myelin-related Nogo receptors, and proteins belonging to the newly discovered class called the Lynx family (Bavelier et al., 2010; Nabel and Morishita, 2013). In most cases, the discovery of these factors was made possible by experimental procedures aimed at manipulating visual experience as a way to affect key molecular factors involved in visual cortex plasticity (Cynader et al., 1976; Mower, 1991; Fagiolini et al., 1994).

These findings raise the question of how information concerning external inputs is translated into activity-dependent activation of molecular pathways controlling gene expression and, ultimately, experience-dependent plasticity. Ideal candidates for this function are epigenetic modifications of chromatin associated with active gene transcription, such as histone acetylation, dimethylation, and phosphorylation (Maya-Vetencourt and Pizzorusso, 2013). Consistently, it has been previously reported that visual experience activates histone acetylation in the visual cortex during the CP (Putignano et al., 2007), and that treatment with trichostatin, a compound that promotes histone acetylation, enhances plasticity in the adult visual cortex (Putignano et al., 2007; Silingardi et al., 2010). This initial evidence, however, was obtained either in animals raised in darkness and quickly exposed to light at different developmental stages, or in adult animals past the closure of the $\mathrm{CP}$, leaving unanswered the question of whether epigenetic regulators are developmentally modulated in the visual cortex of normal light-reared animals, and whether they are causally linked, under physiological conditions, to the closure of the CP.

To address these questions, we took advantage of environmental enrichment (EE), a procedure widely used to increase sensory-motor stimulation and previously associated with a remarkable ability to modulate visual system development and plasticity, both in rodents and in humans (Prusky et al., 2000; Cancedda et al., 2004; Sale et al., 2004; Sale et al., 2007; Guzzetta et al., 2009; Mainardi et al., 2010; Baroncelli et al., 2012; Tognini et al., 2012). We report a tight link between histone acetylation and $\mathrm{CP}$ plasticity, with a strong modulation given by exposure to enriching living conditions.

\section{Materials and Methods}

\section{Animal treatment and surgical procedures}

The study was approved by the Italian Ministry of Public Health (protocol authorized by ministerial decree no. 282/2013-B). The animals were housed in a room with a temperature of $22^{\circ} \mathrm{C}$ and a $12 \mathrm{~h}$ light/dark cycle. In all experiments, experimenters were blinded to experimental conditions.

Monocular deprivation. Rats were anesthetized with avertin (2,2,2tribromoethanol solution, $200 \mathrm{mg} / \mathrm{kg}$ ) at different postnatal days (P; i.e., P21, P28, P35, and > P75). The animals were allowed to recover from anesthesia and were returned to their cages. Eyelid closure was inspected daily until complete cicatrization. Rats showing occasional lid reopening (observed with a surgical microscope) were not included in the experiments.

Rearing environments. EE consisted of a large cage $(100 \times 50 \times 82 \mathrm{~cm})$ with two or more floors linked by stairs, containing several food hoppers, running wheels, and differently shaped objects (platforms, boxes, toys, tunnels, shelters, and nesting material), which were repositioned once per day and completely substituted with others once per week. During the $\mathrm{CP}$, every cage housed at least one female rat with her litter plus three additional filler females; in adulthood, the enriched caged housed six to eight rats of the same gender together. Housing under standard conditions (SCs) consisted of a standard cage $(40 \times 30 \times 20 \mathrm{~cm})$ housing one female rat with her litter (during the $\mathrm{CP}$ ) or two to three adult rats of the same gender. Litter and food were provided ad libitum, and conditions were the same in both environmental conditions. For the assessment of CP plasticity, rearing under SCs or with EE was started the day of mating and continued until the litters reached the ages at which the analyses were performed. For the assessment of visual cortex plasticity in the adult, differential rearing was started at P60.

\section{Single-unit recordings}

After 1 week of $\mathrm{MD}$, animals were anesthetized with intraperitoneal injection of urethane (1.4 g/kg; $20 \%$ solution in saline; Sigma-Aldrich) and placed in a stereotaxic frame. Body temperature was maintained at $37^{\circ} \mathrm{C}$. A hole was drilled in the skull, corresponding to the binocular portion of the primary visual cortex (binocular area Oc1B), contralateral to the deprived eye. A micropipette filled with $\mathrm{NaCl}(3 \mathrm{M})$ was inserted into the cortex, $4.8-5.2 \mathrm{~mm}$ (depending on animal age) lateral with respect to the $\lambda$ point. Both eyes were kept open by means of adjustable metal rings. For single-unit recordings, the positions of receptive fields were mapped using a hand-held stimulator. Only cells with receptive fields within $20^{\circ}$ of the vertical meridian were included in the analysis. Spontaneous activity, peak response, and receptive field size were determined from peristimulus time histograms (PSTHs) recorded in response to computer-generated bars (size, $3^{\circ}$; drifting speed, $38.15^{\circ} / \mathrm{s}$; contrast, 100\%), averaged over 10-20 stimulus presentations. Electrical signals were amplified $(25,000$-fold), bandpass filtered $(500 \mathrm{~Hz}-5 \mathrm{kHz})$, digitized (12 bit resolution), and averaged in synchrony with the stimulus. The analysis was performed off-line by an experimenter who was blind to the treatment conditions of the animals. OD classes were evaluated on the basis of the ratio of contralateral to ipsilateral peak response. More specifically, neurons in ocular dominance class 1 were driven only by stimulation of the contralateral eye; neurons in ocular dominance classes 2 (ratio of contralateral to ipsilateral peak response, $\geq 2$ ) and 3 (ratio of contralateral to ipsilateral peak response, between 1.2 and 2) were binocular and preferentially driven by the contralateral eye; neurons in ocular dominance class 4 were equally driven by the two eyes (ratio of contralateral to ipsilateral peak response, between 0.83 and 1.2); neurons in ocular dominance classes 5 (ratio of contralateral to ipsilateral peak response, between 0.5 and 0.83 ) and 6 (ratio of contralateral to ipsilateral peak response, $\leq 0.5$ ) were binocular and preferentially driven by the ipsilateral eye; and neurons in ocular dominance class 7 were driven only by the ipsilateral eye. For each animal, the bias of the OD distribution toward the contralateral eye [contralateral bias index $(\mathrm{CBI})]$ was calculated as follows: $\mathrm{CBI}=[(N(1)-N(7))+2 / 3(N(2)-N(6))+1 / 3(N(3)-N(5))$ $+\mathrm{NTOT}] / 2 \mathrm{NTOT}$, where $N(i)$ is the number of cells in class $i$, and NTOT is the total number of recorded cells in a specific animal.

Additionally, for each cell an OD score was calculated as follows: $\{[$ peak(ipsi) - baseline(ipsi) $]-[$ peak(contra $)-$ baseline $($ contra $)]\} /$ $\{[$ peak $($ ipsi $)-$ baseline $(i p s i)]+[$ peak $($ contra $)-$ baseline $($ contra $]\}$, where peak is the maximal spike frequency evoked by visual stimulation, ipsi is the ipsilateral eye, baseline is the mean spiking frequency in the absence of stimulation, and contra is the contralateral eye. OD score cumulative distributions were computed for each group.

Cell responsiveness was assessed according to standard criteria in terms of the amplitude of modulation of cell discharge in response to an optimal visual stimulus (peak response divided by spontaneous discharge). Receptive field size was determined from PSTHs, assuming as a visual response the signal above a value equal to the mean spontaneous discharge +2 SDs (Fagiolini et al., 1994).

\section{Injections of suberoylanilide hydroxamic acid}

Suberoylanilide hydroxamic acid (SAHA) was dissolved in 100\% DMSO at a concentration of $50 \mathrm{mg} / \mathrm{ml}$, and then was further diluted to $25 \mathrm{mg} / \mathrm{ml}$ in a solution of $50 \%$ DMSO and $50 \%$ saline. Injections $(25 \mathrm{mg} / \mathrm{kg})$ were given intraperitoneally from P12 to P18 and were alternated daily between left and right sides of the abdomen. All animals were injected during the same time interval each day (11:00 A.M. to 12:00 P.M.).

\section{Visual cliff task}

We used the procedure previously described by Baroncelli et al. (2013). The apparatus consisted of a rectangular arena $\left(100 \times 40 \mathrm{~cm}^{2}\right)$ constructed in poly(vinyl chloride) with black walls and bordered by black curtains to prevent the escape of the animal. The arena was divided into 
two $50 \times 40 \mathrm{~cm}^{2}$ Plexiglas plates. A moving platform, the depth of which could be varied by means of a mechanical scissor jack, was placed below each glass plate. A patterned floor consisting of $3 \mathrm{~cm}$ black-and-white checked photographic paper covered the surface of the platform. Incandescent lamps placed below the two patterned floors illuminate both surfaces to equate the brightness of the two sides. A telecamera was hanging on the apparatus, and was connected to a computer by which the experimenter could observe and record the behavior of the rat. Testing took place in a quiet room. The arena was divided into a shallow and a deep side. On the shallow side, the patterned floor was positioned immediately below the glass plate, while on the deep side the checked platform was moved to $29 \mathrm{~cm}$ below the glass plate. Each animal was placed on the shallow side, and the total time the rat spent exploring each side of the arena was automatically recorded by the Noldus EthoVision system. The trial ended after $5 \mathrm{~min}$. The arena was cleaned between trials with an alcohol solution. A discrimination index was calculated as follows: $\left(t_{s}-t_{d}\right) / t_{\text {tot }}$, where $t_{s}$ and $t_{d}$ are, respectively, the time spent exploring the shallow side and the deep side of the arena, and $t_{\text {tot }}$ is the total time of the test procedure. Each animal was tested only once.

\section{Western blot}

To avoid circadian effects, all animals were killed during the same time interval each day (10:00 A.M. to 12:00 P.M.; light phase). After decapitation, visual cortices and hippocampi were removed rapidly and frozen on dry ice. Tissue was then homogenized in a hypotonic lysis buffer containing the following (in mM): Tris 10, pH 7.5; EDTA 1; sodium pyrophosphate $2.5 ; \beta$-glycerophosphate 1 ; sodium orthovanadate 1 ; and phenylmethylsulfonylfluoride 1 ; with aprotinin $10 \mu \mathrm{g} / \mathrm{ml}$; leupeptin (Sigma-Aldrich) $10 \mu \mathrm{g} / \mathrm{ml}$; and IGEPAL CA-630 (Sigma-Aldrich) $1 \%$. Histones were extracted from the nuclear fraction by the addition of five volumes of $0.2 \mathrm{M} \mathrm{HCl}$ and $10 \%$ glycerol, and the insoluble fraction was pelleted by centrifugation $\left(18,000 \times g\right.$ for $30 \mathrm{~min}$ at $\left.4^{\circ} \mathrm{C}\right)$. Histones in the acid supernatant were precipitated with 10 volumes of ice-cold acetone followed by centrifugation $\left(18,000 \times g\right.$ for $30 \mathrm{~min}$ at $\left.4^{\circ} \mathrm{C}\right)$. The histone pellet was then resuspended in $9 \mathrm{~m}$ urea. Protein concentration was determined by a Bio-Rad assay. Protein extracts of each sample were separated by electrophoresis and blotted; filters were blocked and incubated overnight at $4^{\circ} \mathrm{C}$ with primary antibodies (anti-acetyl-H3, 1:300 dilution, Millipore; anti-H3, 1:300 dilution, Millipore). Blots were then rinsed and incubated in infrared-labeled secondary antibodies (anti-mouse IRDye 680LT 1:20000 or anti-rabbit 800CW 1:20,000, Li-Cor Biosciences). Filters were scanned using an Odyssey IR scanner (Li-Cor), and densitometry analysis was performed with Image Studio Software version 3.1 (Li-Cor).

\section{Chromatin immunoprecipitation}

To avoid circadian effects, all animals were killed during the same time interval each day (10:00 A.M. to 12:00 P.M.; light phase). Visual cortices were removed, and the fresh tissue was immediately frozen and stored at $-80 \mathrm{C}^{\circ}$. Chromatin immunoprecipitation (ChIP) was performed according to the ChIP Kit (ab500, Abcam) guidelines. Briefly, tissue was cross-linked using $1 \%$ formaldehyde (10 $\mathrm{min}$ at room temperature), and the reaction was stopped by adding $0.125 \mathrm{~m}$ glycine. Samples were then sonicated, and DNA was fragmented (400-1500 bp range), using the Bioruptor (Diagenode) for $17 \mathrm{~min}$ (30 s "ON," $30 \mathrm{~s}$ "OFF," power high) at $4^{\circ} \mathrm{C}$. Protein-DNA complexes were immunoprecipitated using protein A-coated beads, previously incubated with $1 \mu \mathrm{g}$ of the specific antibody anti-AcH3 (lys 9-14; catalog \#06-599, Millipore). Samples were incubated overnight at $4^{\circ} \mathrm{C}$, and the beads were washed and treated with Proteinase $\mathrm{K}$ for $30 \mathrm{~min}$ at $55^{\circ} \mathrm{C}$. Finally, DNA was purified according to the manufacturer protocol and subjected to quantitative PCR.

\section{Real-time PCR}

Levels of specific histone modifications at the P1 and P3 BDNF gene promoter were determined by measuring the amount of these promoters in chromatin immunoprecipitates by use of real-time PCR (Applied Biosystems Step One, Thermo Fisher Scientific). Input DNA (nonimmunoprecipitated DNA) and immunoprecipitated DNA were PCR amplified in triplicate using SsoAdvaced Universal SYBR Green Supermix (catalog \#172-5271, Bio-Rad). The following primers were used to selectively amplify portions of BDNF P1, BDNF $\mathrm{P} 3$, and $\beta$-tubulin promoters: $\mathrm{P} 1$ : forward, $5^{\prime}$-CCCCGCTGCGCTTTTCTGGT-3'; reverse 5'CAATTTGC ACGCCGCTCCTTTAC3'; P3: forward, 5'-GCGCGGAATTCTGATTC TGGTAAT-3'; reverse, $5^{\prime}$ GAGAGGGCTCCACGCTGCCTTGACG-3'; $\beta$ tubulin: forward, 5'-TAGAACCTTCCTGCGGTCGT-3'; reverse, $5^{\prime}$ TTTTCTTCTGGGCTGGTCTC-3'.

The relative quantities of immunoprecipitated DNA fragments were calculated by using the threshold cycle number $(\mathrm{Ct})$ obtained during the exponential growth of the PCR products and normalized to the mean input Ct values of control animals (Tognini et al., 2011).

Moreover, total RNA from rat visual cortex samples was purified by RNA nucleospin (Macherey-Nagel) as recommended by the manufacturer. cDNA was reverse transcribed using the Reverse Transcriptase Core Kit (Eurogentech). The following primers were used to amplify BDNF exons (IV and IX). Tubulin was used as an internal control for normalization: BDNF exon IV mRNA: forward, TGCGAGTATTACC TCCGCCAT; reverse, TCACGTGCTCAAAAGTGTCAG; and BDNF exon IX mRNA: forward, GAGAAGAGTGATGACCATCCT; reverse, TCACGTGCTCAAAAGTGTCAG.

Quantitative real-time PCRs were performed using the SYBR PCR Mastermix (Applied Biosystems) on the Step One Plus Real-Time PCR System (Applied Biosystems).

\section{Results \\ OD plasticity in developing rats}

We first examined, at different postnatal ages, OD plasticity in response to 1 week of MD in rats reared under either SCs or with EE. We used single-unit recordings in anesthetized animals to calculate the CBI, which reflects the proportion of cells preferentially driven by the eye contralateral to the brain side from where recordings are made. We found robust and equal levels of OD plasticity in SC animals at P28 $(n=9)$ and P35 $(n=8$; one-way ANOVA, post hoc Holm-Sidak method, $p=0.964)$, with a significant decay in plasticity occurring at P42 $(n=6)$ with respect to the previous ages (Fig. 1A; one-way ANOVA, post hoc HolmSidak method, $p<0.001$ for both comparisons). We also performed a finer comparison of OD distributions, computing a normalized OD score of single neurons. Consistently, the OD score distribution for P28 (202 cells) and P35 SC animals (181 cells) was shifted in favor of the not-deprived eye and did not differ between each other (Kolmogorov-Smirnov test, $p=$ 0.924 ), whereas it was significantly changed in P42 rats (131 cells) with respect to both $\mathrm{P} 28$ and $\mathrm{P} 35$, as a result of a reduction in the shift of OD in favor of the not-deprived eye (Fig. $1 B ; p<0.001$ for both comparisons). The decay of OD plasticity turned out to be accelerated in rats raised with EE. Indeed, we found that the CBI of EE animals was robustly shifted toward the not-deprived eye only at P28 $(n=5)$, when it significantly differed from that recorded at both P35 $(n=7)$ and P42 $(n=5$; one-way ANOVA, post hoc Holm-Sidak method, $p<0.01$ for both comparisons); differently from SC rats, the CBI computed for EE rats already appeared to be significantly increased at P35, with levels comparable to those recorded 1 week later, at $\mathrm{P} 42$, reflecting a 1 week acceleration in the decay of visual cortex plasticity (Fig. $1 C ; p=$ 0.299 ). This result was confirmed by the OD score distribution, which at P28 (97 cells) was found to differ from that at both P35 (161 cells) and P42 (104 cells) EE animals (Kolmogorov-Smirnov test: $p<0.01$ for P28 vs P35; $p<0.001$ for P28 vs P42), while no difference in OD score distribution was detected between P35 and $\mathrm{P} 42$ (Fig. $1 D ; p=0.088$ ).

To better compare OD plasticity between rats raised under SCs and with EE, we calculated for each animal a plasticity index, expressed as 1 - CBI, a parameter that is thus directly proportional to OD plasticity levels (Fig. $1 E$ ). A two-way ANOVA of this parameter showed an interaction between age and environmen- 
A

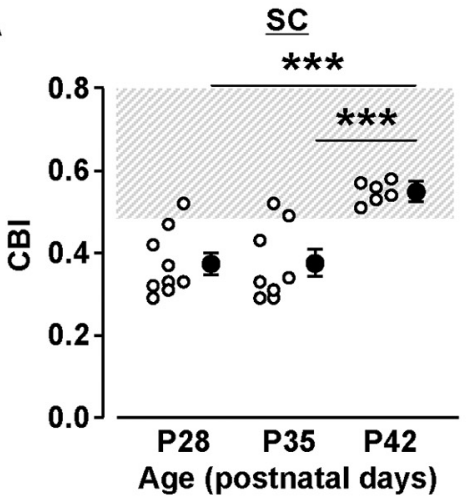

C

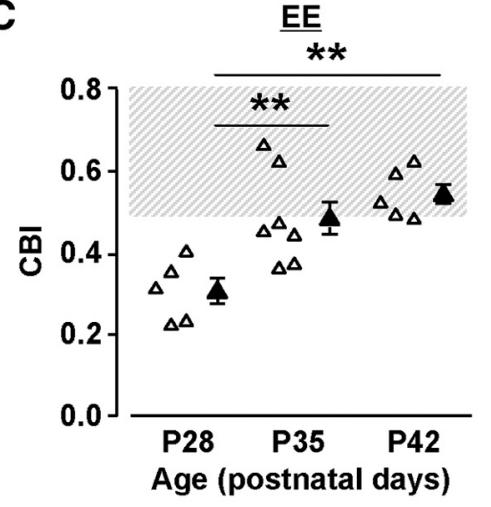

E

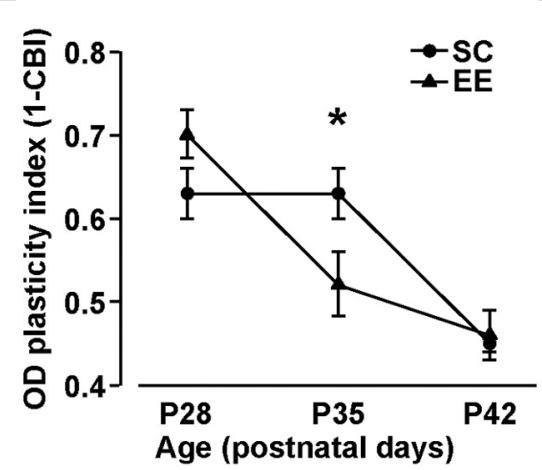

B

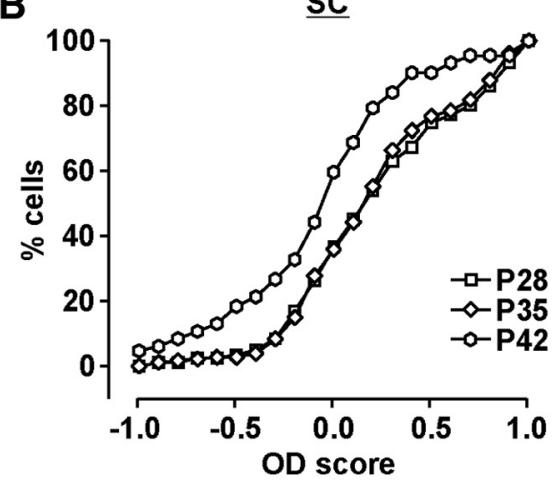

D

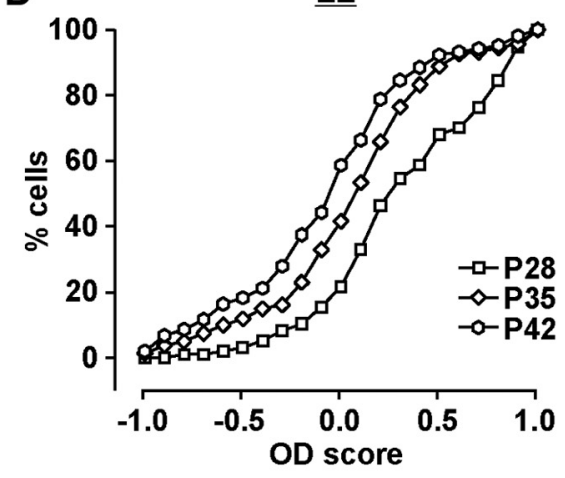

F

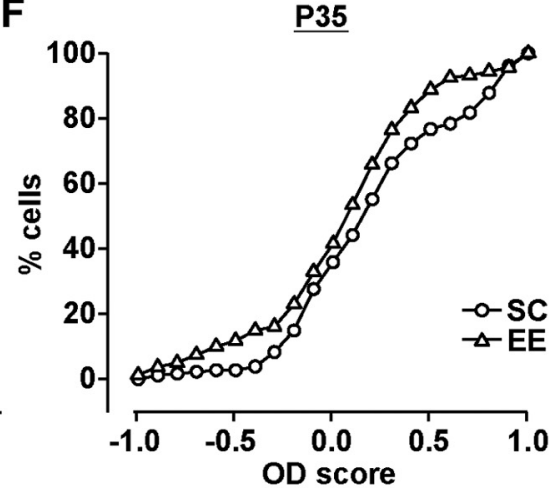

Figure 1. Early environmental enrichment accelerates the critical period for OD plasticity. $\boldsymbol{A}$, Filled circles represent the average CBI \pm SEM for each experimental group; open symbols represent individual CBIs for each animal. At P28 and P35, the CBls of $S C$-reared animals were comparable, indicating a clear OD shift toward the open eye $(P 28: n=9, C B I=0.37 \pm 0.03 ; P 35: n=8$, $\mathrm{CBI}=0.38 \pm 0.03$; one-way ANOVA, post hoc Holm-Sidak method, $p=0.964)$; at $\mathrm{P} 42$, the $\mathrm{CBI}$ of SC-reared rats differed from those of the previous two ages $(n=6, \mathrm{CB}=0.55 \pm 0.01 ; p<0.001$ for both comparisons) as a result of a reduced $0 \mathrm{D}$ plasticity. The gray box denotes the $C B I$ range in adult normal animals calculated as the mean $\pm 2 * S D$ from recordings of adult naive rats. $\boldsymbol{B}$, Analogously to CBI, the OD score distributions for P28 animals ( $n=9 ; 202$ cells) and P35 animals ( $n=8,181$ cells) did not differ (Kolmogorov-Smirnov test, $p=0.924$ ), whereas the $0 \mathrm{D}$ score distribution for P42 rats ( $n=6,131$ cells) was different from those of the two other ages ( $p<0.001$ for both comparisons). $C$, The CBI of enriched animals was shifted toward the not-deprived eye only at P28, when it significantly differed from that at both P35 and P42 (P28: $n=5, C B I=0.30 \pm 0.03 ; P 35: n=7, C B I=$ $0.48 \pm 0.04 ; \mathrm{P} 42: n=5, \mathrm{CBI}=0.54 \pm 0.03$; one-way ANOVA, post hoc Holm-Sidak method, $p<0.01$ for both comparisons); starting from $\mathrm{P} 35$, enriched rats displayed an earlier closure of OD plasticity, as indicated by their higher $\mathrm{CBI}$, which did not differ from that recorded at P42 ( $p=0.299)$. The gray box denotes the (BI range in adult normal animals calculated as the mean $\pm 2 * S D$ from recordings of adult naive rats. $D$, The results obtained with the $C B I$ were confirmed by those with computation of $0 D$ score in enriched animals: indeed, the OD score distribution for P28 animals ( $n=8 ; 97$ cells) differed from that at both P35 ( $n=7,161$ cells) and P42 ( $n=5,104$ cells; Kolmogorov-Smirnov test, $p<0.01$ for P28 vs P35; $p<0.001$ for P28 vs P42). The 0D score distributions for P35 and P42 groups were not different $(p=0.088)$. $E$, A plasticity index for each animal was calculated as $1-C B I$. Two-way ANOVA showed an interaction between age and environmental housing conditions $(p<0.05)$. A post hoc Holm-Sidak test revealed a difference $\left({ }^{*}\right)$ at $\mathrm{P} 35$ between $\mathrm{SC}$ and EE groups $(p<0.05) . \boldsymbol{F}, 0 \mathrm{D}$ score cumulative distributions for the P35 SC and EE groups differed (Kolmogorov-Smirnov test, $p<0.05$ ). The asterisks indicates statistical significance: ${ }^{*} p<0.05 ;{ }^{* *} p<0.01$; ${ }^{* * *} p<0.001$. Data are expressed as the mean \pm SEM.

tal housing condition $(p<0.05)$. A post hoc Holm-Sidak test revealed a difference between the SC and EE groups only at P35 $(p<0.05)$, when the OD score cumulative distribution was also found to differ between the two groups (Fig. 1F; Kolmogorov-Smirnov test, $p<0.05$ ). No difference was found between SC and EE animals in terms of either cell responsiveness (two-way ANOVA on ranks, $p=$ 0.243 ) or receptive field size distribution (Fig. $2 A, B$; two-way ANOVA, $p=0.474$ ). Thus, these data demonstrate that an early exposure to EE accelerates the closure of the CP for OD plasticity in the primary visual cortex.

It has been previously suggested that altering the timing of the $\mathrm{CP}$ for OD plasticity might result in abnormal visual development (Wang et al., 2013). Thus, we also evaluated whether rearing in EE from birth affected stereopsis abilities at P45 (i.e., at the end of the CP). We tested notdeprived animals raised under SCs and with $\mathrm{EE}$ in the visual cliff task, evaluating their spontaneous preference for the deep side or the shallow side of the arena (Baroncelli et al., 2013; Fig. 3A). We found that both groups of animals displayed a clear preference for the shallow side of the arena (SC, $n=17$; EE, $n=12$ ) without a significant difference between them (oneway ANOVA, post hoc Holm-Sidak method, $p=0.409$; Fig. 3B). Moreover, the two groups of animals did not differ in their respective exploration index from adult naive rats (adult $\mathrm{BIN}, n=9$; oneway ANOVA, post hoc Holm-Sidak method, $p=0.147$ and $p=0.409$ respectively), which instead exhibited a marked difference compared with monocularly deprived animals in which stereopsis abilities were hampered by imposing singleeye vision through an eyelid suture [adult monocular vision (MON), $n=9$; one-way ANOVA, post hoc Holm-Sidak method, $p<0.05$ for all comparisons with adult MON animals]. Together, these results indicate that an accelerated CP time course did not alter the maturation of visual depth perception abilities in EE rats.

EE enhances histone acetylation in the primary visual cortex

Since changes in the functional state of chromatin have been reported to be involved in visual system developmental plasticity (Putignano et al., 2007), we measured, in the visual cortex of pups reared either with EE or under SCs, the levels of acetylated histone H3-Lys 9 $(\mathrm{AcH} 3)$, expressing the data as the ratio between the intensity of the Western blot 
A

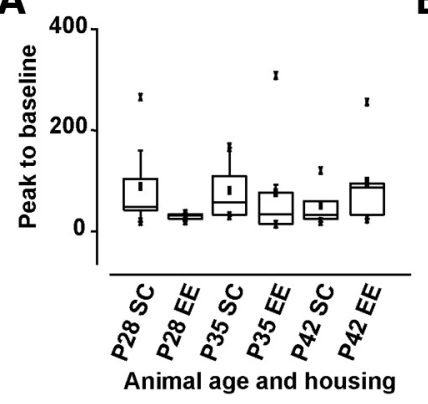

B

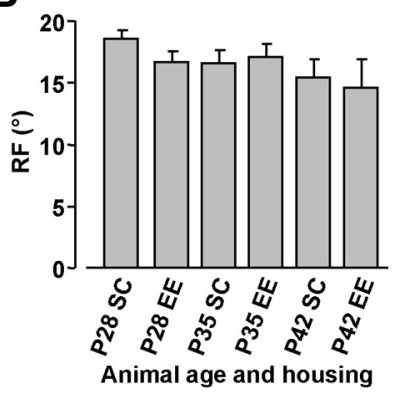

Figure 2. Similar basic cell properties in enriched and standard-reared animals. We analyzed cell responsiveness and receptive field (RF) size in the same animals in which OD evaluation was performed. $A$, Cell responsiveness for each unit was expressed as the ratio between the peak response and the mean baseline activity obtained by optimal stimulation of the preferred eye. Data are represented as box charts. For each box chart, the central horizontal line represents the median value, and the other two horizontal lines are the 25th and 75th percentiles; error bars denote the 5th and 95th percentiles; square symbols denote the mean value. No statistical difference in cell responsiveness was found among the experimental groups (two-way ANOVA on ranks, $p=0.243) \cdot \boldsymbol{B}$, RF size for each cell was calculated on the basis of the peristimulus time histogram obtained by optimal stimulation of the preferred eye and was expressed in degrees $\left({ }^{\circ}\right)$ of visual angle. No differences in receptive field size distribution were detected among the experimental groups (mean RF size: $\mathrm{P} 28-\mathrm{SC}=18.6^{\circ} \pm 0.7^{\circ} ; \mathrm{P} 28-\mathrm{EE}=16.7^{\circ} \pm 0.9^{\circ} ; \mathrm{P} 35-$ $\mathrm{SC}=16.6^{\circ} \pm 1.1^{\circ} ; \mathrm{P} 35-\mathrm{EE}=17.1^{\circ} \pm 1.1^{\circ} ; \mathrm{P} 42-\mathrm{SC}=15.5^{\circ} \pm 1.5^{\circ} ; \mathrm{P} 42-\mathrm{EE}=14.6^{\circ} \pm 2.3^{\circ} ;$ two-way ANOVA, $p=0.474)$. Data are expressed as the mean \pm SEM.

bands of $\mathrm{AcH} 3$ and total $\mathrm{H} 3(\mathrm{AcH} 3 / \mathrm{H} 3$ ratio; SC: $n(\mathrm{P} 15)=11$, $n(\mathrm{P} 25)=11, n(\mathrm{P} 45)=9, n(\mathrm{P} 60)=9, n(\mathrm{P} 90)=8$; EE: $n(\mathrm{P} 15)=$ $8 ; n(\mathrm{P} 25)=6 ; n(\mathrm{P} 45)=7 ; n(\mathrm{P} 60)=6)$. First, we found a developmental regulation of $\mathrm{AcH} 3$ levels in the primary visual cortex of SC rats, with low levels detectable at P15, a peak at $\sim \mathrm{P} 25$, and then a progressive decay up to P90 (Fig. 4A, B; effect of age, $p<$ 0.001, Kruskal-Wallis one-way ANOVA on ranks). Then, we measured developmental changes in the $\mathrm{AcH} 3 / \mathrm{H} 3$ ratio between $\mathrm{SC}$ and $\mathrm{EE}$ rats (Fig. 4C,D). We found that the $\mathrm{AcH} 3 / \mathrm{H} 3$ ratio was significantly increased in the visual cortex of EE animals at P15 (Mann-Whitney rank sum test, $p<0.05$ ); no difference between SC and EE groups was instead detected at the other ages tested $(t$ test, $p=0.994$ for P25; Mann-Whitney rank sum test, $p=0.535$ for P45; $t$ test, $p=0.850$ for P60). These results indicate a developmental regulation of histone acetylation in the primary visual cortex, with early exposure to EE resulting in an upregulation of $\mathrm{AcH} 3$ levels.

To evaluate whether the regulation of histone acetylation by EE was specific to the cerebral cortex, we also assessed AcH3 levels in the hippocampus of EE and SC rats at P15. We found increased $\mathrm{AcH} 3$ levels in EE compared with SC animals ( $t$ test, $p<0.05)$.

\section{Histone acetylation at the BDNF gene promoter}

Chromatin remodeling is a dynamic process that modulates gene expression, with hyperacetylation at promoters usually loosening the structural interactions between DNA and histones, allowing the transcriptional machinery access to the gene promoters, thus resulting in an increase in gene activity. To better understand the molecular factors by which EE exerts its impact on visual cortex plasticity, we studied histone acetylation at the promoters of the gene encoding BDNF, a factor crucially involved in developmental plasticity in the primary visual cortex and in the effects of early exposure to EE (Huang et al., 1999; Cancedda et al., 2004; Sale et al., 2004; Landi et al., 2007).

Focusing on P15, the age at which maximal changes in total histone acetylation levels were found between rats reared with EE

A

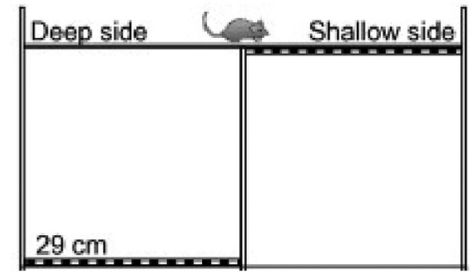

B

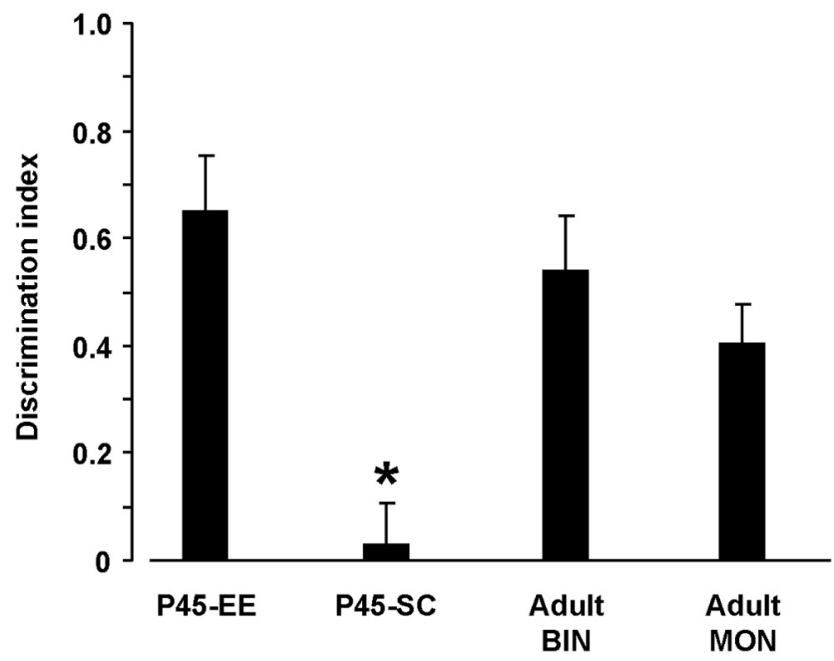

Figure 3. Depth perception abilities are not altered by the acceleration of critical period timing in enriched rats. $A$, In an explorative version of the visual cliff task, P45 SC animals ( $n=$ 17 , exploration index $=0.401 \pm 0.073$ ) and EE animals $(n=12$, exploration index $=0.541 \pm$ 0.100 ) displayed a preference for the shallow side, thus revealing the maturation of proper stereopsis abilities. $\boldsymbol{B}$, The discrimination index scores did not differ between the two experimental groups (one-way ANOVA, post hoc Holm-Sidak method, $p=0.409$ ), and, importantly, it was also not significantly different from that recorded in adult naive animals with normal binocular vision (adult BIN: $n=9$, exploration index $=0.652 \pm 0.101$; one-way ANOVA, post hoc Holm-Sidak method, $p=0.147$ and $p=0.409$ respectively); instead, adult rats with one eye closed through eyelid suture exhibited a prominent change in their discrimination index (adult MON: $n=9$; exploration index $=0.028 \pm 0.077$ ), equally exploring the deep and the shallow sides of the arena (one-way ANOVA, post hoc Holm-Sidak method, $p<0.05$ for all comparison with adult MON animals). The asterisk indicates statistical significance: ${ }^{*} p<0.05$. Data are expressed as the mean \pm SEM.

and under SCs, we specifically examined, via chromatin immunoprecipitation followed by real-time PCR, how histone modifications were altered at both $\mathrm{P} 1$ and $\mathrm{P} 3 \mathrm{BDNF}$ gene promoters, two of the four BDNF promoters (P1 through $\mathrm{P} 4)$ that can differentially regulate BDNF expression in the rat brain (Metsis et al., 1993). While no difference between the two groups of animals was found for BDNF P1 H3 acetylation ( $t$ test, $p=0.475$ ), we found a significant increase in BDNF P3 H3 acetylation in the visual cortex of EE subjects $(n=4)$ with respect to SC animals $(n=4$; Fig. $5 B$; $t$ test, $p<0.05)$. As control, we also measured levels of histone acetylation at the promoter of the $\beta$-tubulin gene, which is expressed in the visual cortex, but whose expression levels are expected to be unchanged after exposure to EE. We found no difference in $\mathrm{H} 3$ acetylation at the $\beta$-tubulin promoter between SC and EE rats ( $n=4$ for both groups; $t$ test, $p=0.181$ ). These findings indicate that the observed changes in histone acetylation at the BDNF $\mathrm{P} 3$ promoter did not depend on a difference between EE and SC animals in terms of global histone acetylation.

Finally, we also measured by real-time PCR the P3/total mRNA ratio for the BDNF gene at P15. Notably, we found that the BDNF P3/total 
A

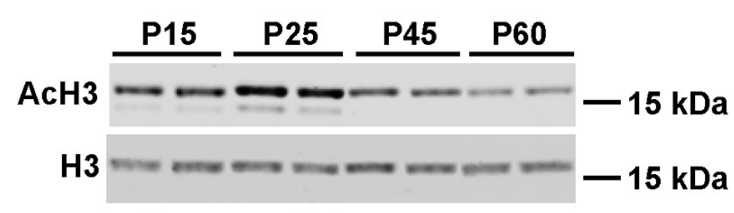

C

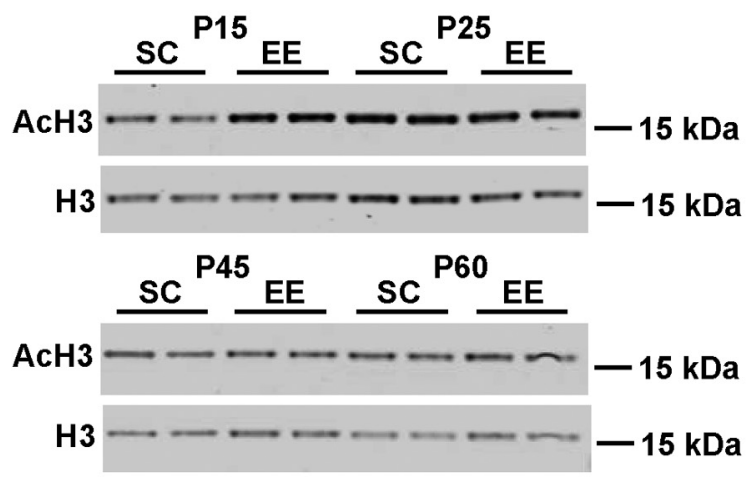

B

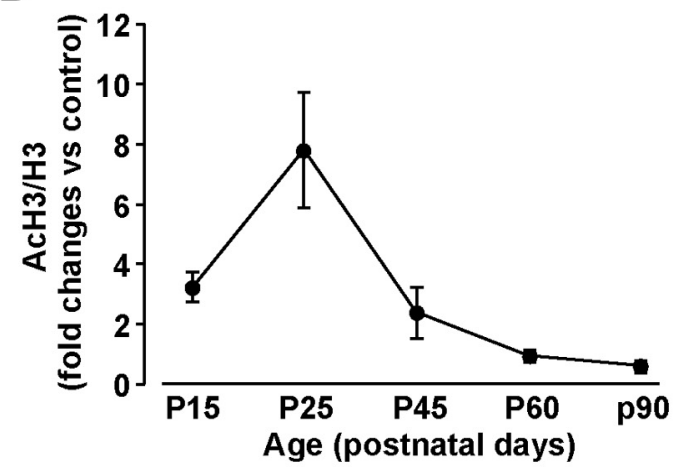

D

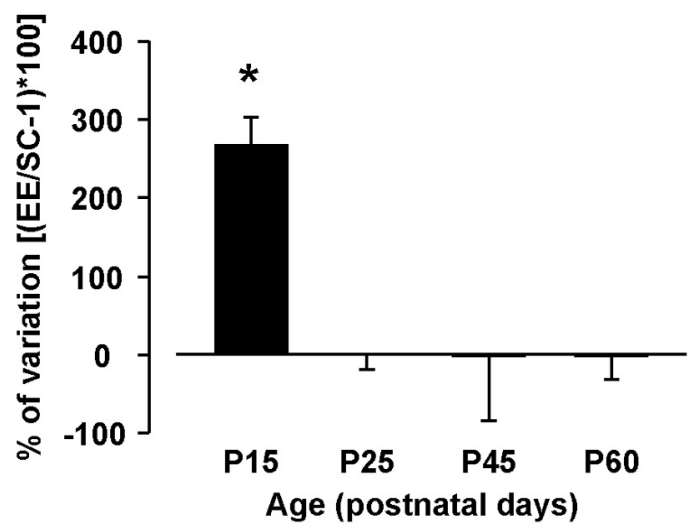

Figure 4. Developmental regulation of histone acetylation in $\mathrm{V1}$ : effects of exposure to $\mathrm{EE}$. The ratio between the intensity of the bands of acetyl-H3 and total $\mathrm{H} 3$ ( $\mathrm{AcH} 3 / \mathrm{H} 3 \mathrm{ratio}$ ) was used as an index for measuring the amount of acetylated H3.A, A representative immunoblot showing protein levels in the visual cortex of SC-reared rats at P15 ( $n=11), \mathrm{P} 25$ ( $n=11), \mathrm{P} 45$ ( $n=9), \mathrm{P} 60(n=$ 9), and $\mathrm{P} 90(n=8)$. In each gel, the $\mathrm{AcH} 3 / \mathrm{H} 3$ ratio measured for all samples was normalized to the mean ratio calculated for the control group (P60 animals). $\boldsymbol{B}, \mathrm{Quantification}$ of acetylated $\mathrm{H} 3$ levels showed a developmental regulation in the primary visual cortex of SC-reared rats. A Kruskal-Wallis one-way ANOVA on ranks revealed a significant effect of age ( $p<0.001)$. $C$, A representative Western blot gel displaying protein levels in the visual cortex of P15, P25, P45, and P60 animals reared either in SC or EE conditions (EE-P15, $n=4 ; \mathrm{EE}-\mathrm{P} 25, n=6 ; \mathrm{EE}-\mathrm{P} 45, n=7 ; \mathrm{EE}-\mathrm{P} 60, n=6$ ). In each gel, the $\mathrm{ACH} 3 / \mathrm{H} 3$ ratio measured for all samples was normalized to the mean ratio calculated for the control group (SC animals for each age). $D$, Percentage of variation of $\mathrm{AcH} 3 / \mathrm{H} 3$ ratio in the visual cortices of rats reared under SCs and with EE computed as $[(E E / S C-1) \times 100]$ at different ages. Acetylated H3 levels were significantly increased in the visual cortex of EE animals at P15 (Mann-Whitney rank sum test, $p<0.05$ ), while they did not differ between $\mathrm{SC}$ and EE groups at the other ages tested ( $t$ test, $p=0.994$ for P25; Mann-Whitney rank sum test, $p=0.535$ for P45; $t$ test, $p=0.850$ for P60). The asterisk indicates statistical significance: ${ }^{*} p<0.05$. Data are expressed as the mean \pm SEM.

mRNA ratio was significantly increased in EE rats compared with SC rats (Fig. $5 C ; n=4$ for both groups; $t$ test, $p<0.05$ ), which is consistent with the increased $\mathrm{P} 3 \mathrm{H} 3$ acetylation.

A causal link between histone acetylation and CP plasticity To assess whether the early increase in $\mathrm{H} 3$ acetylation detected in the visual cortex of EE rats was functionally linked to the accelerated decline in visual cortical plasticity displayed by the same group, we analyzed the effects of MD in SC animals treated with SAHA, a deacetylase inhibitor that has been widely used to increase histone acetylation in the brain (Guan et al., 2009; Kilgore et al., 2010). To better mimic the effects of exposure to EE, SAHA was intraperitoneally injected for $7 \mathrm{~d}$ starting at P12. Then, OD plasticity was assessed at P35 (MD from P28 to P35). First, we assessed whether treatment with SAHA was able to replicate the early increase in $\mathrm{H} 3$ acetylation previously documented in the visual cortex of EE rats. We found that the primary visual cortex of SC-SAHA rats $(n=6)$ displayed, at P15, increased amounts of AcH3 compared with SC animals (Kruskal-Wallis one-way ANOVA on ranks vs control, post hoc Dunn's method, $p<0.05$ ), while histone acetylation levels in vehicle-treated age-matched rats (50\% DMSO in saline; $n=6$ ) were not different from those of controls (Kruskal-Wallis one-way ANOVA on ranks vs control, post hoc Dunn's method; Fig. $6 A, B)$. Second, we performed single-unit recordings in SC animals treated with SAHA and subjected to MD starting at P28. Similar to what was found previously in EE animals, we found an earlier decay in OD plasticity in SAHA-treated animals $(n=5)$ with respect to untreated rats raised under SCs (one-way ANOVA vs control, post hoc HolmSidak method, $p<0.05$ ), while animals to which the vehicle solution (DMSO; $n=7$ ) was administered showed, as expected, a mean CBI shifted in favor of the not-deprived eye, like rats raised under SCs (Fig. 7A; $p=0.422$ ). The comparison of OD score distributions confirmed these results. Indeed, the OD score cumulative distribution did not differ between SC and vehicletreated animals (Kolmogorov-Smirnov test, $p=0.540$ ), whereas it was statistically different in SAHA-treated rats (KolmogorovSmirnov test, $p<0.01$ ), further demonstrating that increased levels of histone acetylation induce an acceleration of visual cortex development (Fig. 7B). No difference was found among animals raised under SCs, and those treated with SAHA and DMSO in terms of either cell responsiveness (Fig. 7C; Kruskal-Wallis one-way ANOVA on ranks, $p=0.939$ ) or receptive field size distribution (Fig. 7D; one-way ANOVA, $p=0.289$ ). These results together demonstrate that the early increase in $\mathrm{H} 3$ acetylation found in rats exposed to EE is causally linked to the accelerated decline of visual cortical plasticity induced by the enriched experience. 
EE in adulthood increases $\mathrm{H} 3$ acetylation and reinstates $O D$ plasticity in the rat visual cortex

To assess whether the developmental downregulation of experience-dependent histone acetylation could have a functional consequence for visual cortical plasticity, we took advantage of the remarkable capability of EE to reinstate OD plasticity in adult rats past the end of the CP (Baroncelli et al., 2010). After $14 \mathrm{~d}$ of differential rearing in adulthood (starting from P60), SC and EE animals were monocularly deprived and maintained under their respective rearing conditions for another $7 \mathrm{~d}$. Then, we recorded singleunit activity to assess OD plasticity. We found that the CBI of EE rats $(n=8)$ was reduced in response to $\mathrm{MD}$ with respect to that of both SC rats $(n=7)$ and naive adult rats ( $n=5$; no MD-SC rats), as a result of a plastic change in eye preference displayed by visual cortical neurons (Fig. 8A; one-way ANOVA, post hoc Holm-Sidak method, $p<0.01$ for both comparisons). No statistical difference was present among the three experimental groups in terms of cell responsiveness (Fig. 8B; Kruskal-Wallis one-way ANOVA on ranks, $p=0.749$ ) or receptive field size distribution of the cell population (Fig. 8C; one-way ANOVA, $p=0.515$ ).

Finally, we investigated whether the reopening of CP plasticity in adult EE rats was accompanied by changes at the histone acetylation level. We found an upregulation of $\mathrm{AcH} 3$ in the primary visual cortex of not-deprived animals exposed to EE for $14 \mathrm{~d}(n=7)$ compared with controls raised under SCs ( $n=8$; Fig. $8 D ; t$ test, $p<0.05)$. An increased AcH3 acetylation was also found in the primary visual cortex of MD-EE rats $(n=8)$ compared with MD-SC controls $(n=8$; $t$ test, $p<$ 0.05 in both cases). Thus, exposure to EE is able to raise histone acetylation in the adult visual cortex, leading to a reopening of the CP for OD plasticity.

\section{Discussion}

It has been previously demonstrated that an epigenetic remodeling of chromatin controls developmental plasticity in the visual cortex (Putignano et al., 2007). To date, however, three main questions have remained open in this fundamental field. Which is the physiological time course of histone post-translational modifications during the CP? Is it possible, by manipulating the developmental epigenetic state of chromatin in the visual cortex, to modulate plasticity levels during the CP? How can we change histone acetylation levels in the adult brain in a noninvasive manner, reopening plasticity windows through procedures suitable for human application?

B expressed as the mean \pm SEM.

\section{A BDNF gene}
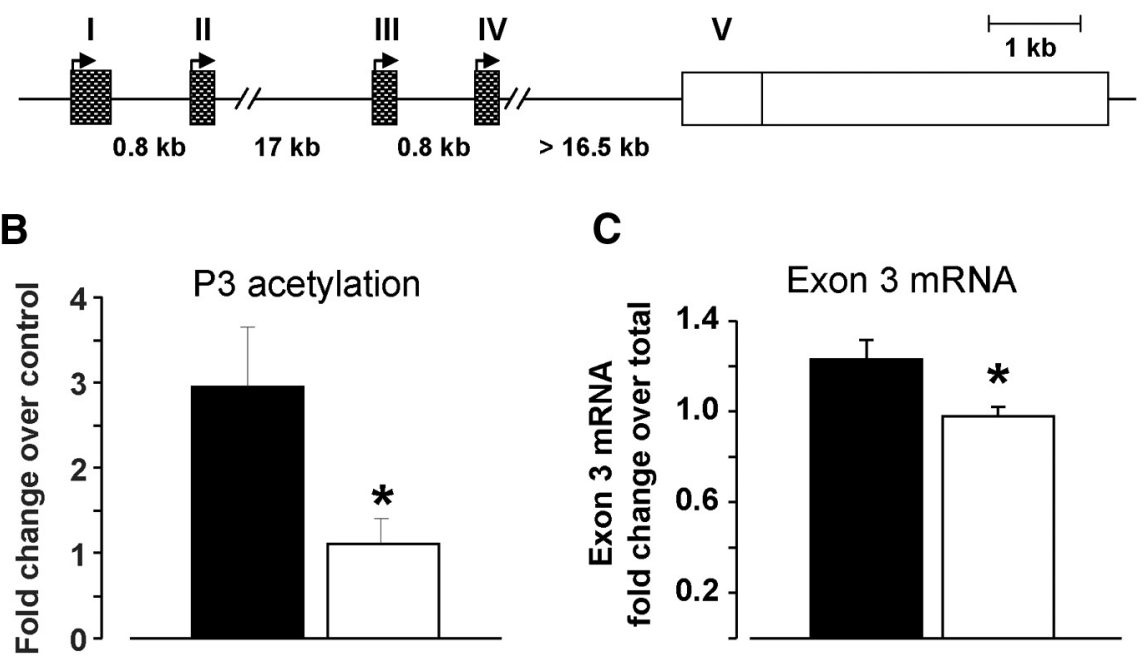

C

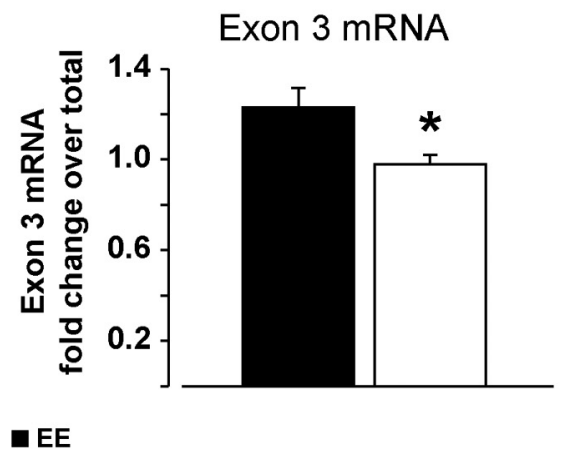

Figure 5. Exposure to $\mathrm{EE}$ enhances $\mathrm{H} 3$ acetylation at the BDNF promoter 3. $\boldsymbol{A}$, Schematic diagram of the structure of the rat $\mathrm{BDNF}$ gene. Boxes represent exons, and lines represent introns. BDNF exons I to IV are shown as checkered boxes and are directed by promoters I to IV, shown as right-angled arrows. $\boldsymbol{B}$, Levels of $\mathrm{H} 3$ acetylation at the BDNF promoter 3 in rats reared with EE and under SCs at P15 ( $n=4$ in both groups), calculated as mean fold changes over SC-reared controls. A t test revealed a significant increase in the fold change for EE rats compared with SC-reared animals $(p<0.05)$. C, Levels of exon 3 BDNF mRNA normalized over total BDNF mRNA in rats reared with EE and under SCs at P15 ( $n=4$ in both groups). A t test revealed a significant increase in the fold change for EE rats compared with SC-reared animals $(p<0.05)$. The asterisk indicates statistical significance: ${ }^{*} p<0.05$. Data are

A

Figure 6. Injection of a histone deacetylase inhibitor mimics increased $\mathrm{H} 3$ acetylation. $A, A$ representative Western blot filter displays protein levels in the visual cortex of animals raised under $\mathrm{SCS}(n=8)$, and those treated with SAHA $(n=5)$ and DMSO $(n=7)$ at $\mathrm{P} 15$. In each gel, the $\mathrm{ACH} 3 / \mathrm{H} 3$ ratio measured for all samples was normalized to the mean ratio calculated for the control group (SC of the same age). $\boldsymbol{B}$, Quantification of acetylated $\mathrm{H} 3$ levels showed that acetylation levels were significantly increased in the visual cortex of SAHA animals, while the $\mathrm{ACH} 3 / \mathrm{H} 3$ ratio of DMSO rats was not different from that measured in the SC control group (Kruskal-Wallis one-way ANOVA on ranks vs controls, post hoc Dunn's method). The asterisk indicates statistical significance: ${ }^{*} p<0.05$. Data are expressed as the mean \pm SEM.

Here, we provided answers to these still open issues. First, we demonstrated that $\mathrm{CP}$ plasticity in the rat primary visual cortex is controlled at an epigenetic level through histone posttranslational modifications. Indeed, we showed that $\mathrm{H} 3$ histone acetylation is developmentally regulated in the visual cortex during the $\mathrm{CP}$, with a peak at $\sim 1$ week before that for OD plasticity. Second, a physiological paradigm used to cause an increase in $\mathrm{H} 3$ histone acetylation (i.e., exposure to early EE) turned out to accelerate the closure of the plastic window, suggesting a causal link between these two events. We provided a direct demonstration of this hypothesis, showing that treatment with the histone deacety- 
A
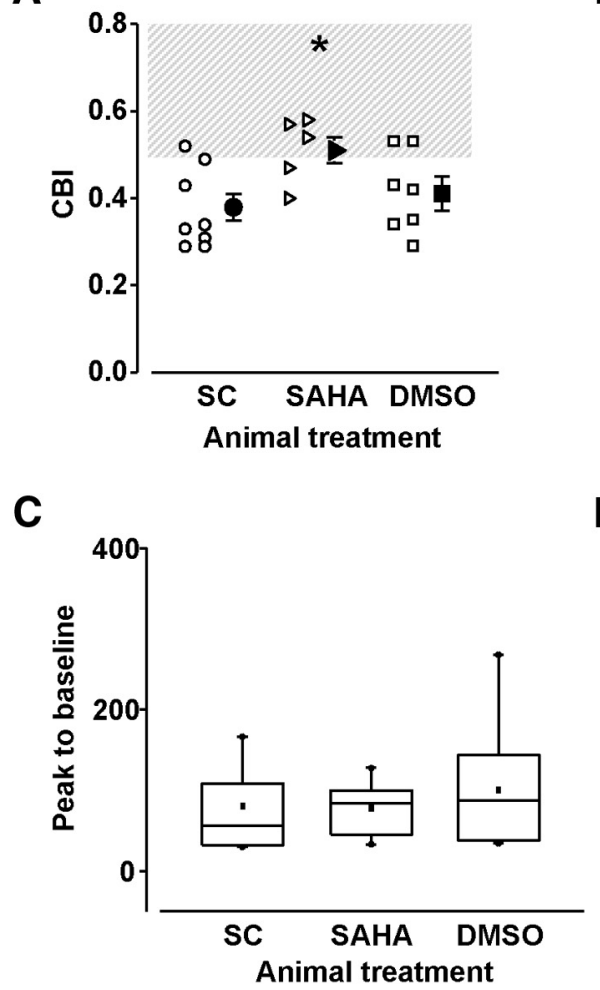

B

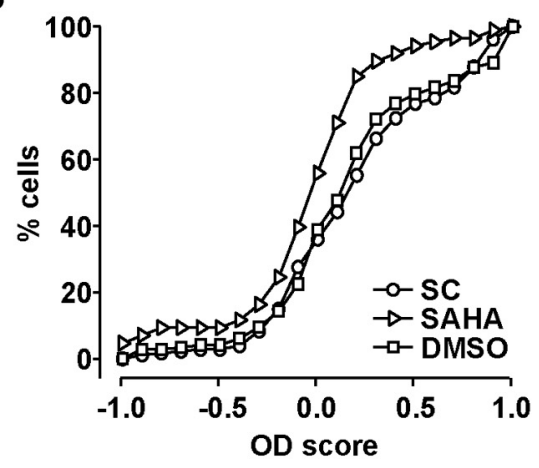

D

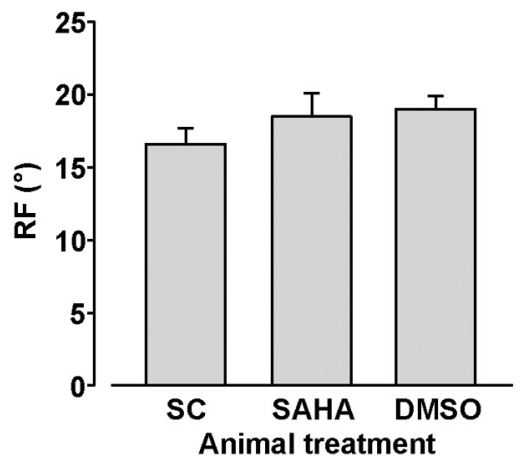

Figure 7. Injection of a histone deacetylase inhibitor mimics accelerated closure of $0 D$ plasticity. $A, C B I$ values for animals raised under SCS $(n=8,0.38 \pm 0.03)$, and those treated with SAHA $(n=5,0.51 \pm 0.03)$ and DMSO $(n=7,0.41 \pm 0.04)$. Filled circles represent the average $C B I \pm S E M$ for each experimental group; open symbols represent individual CBIs for each animal. At P35, the CBI of DMSO-treated rats was not significantly different from that of SC animals, whereas the visual cortex driving force in SAHA rats remained significantly shifted toward the contralateral (deprived) eye (one-way ANOVA vs control, post hoc Holm-Sidak method). The gray box denotes the $C B I$ range in adult normal animals calculated as the mean $\pm 2 *$ SD from recordings of adult naive rats. $\boldsymbol{B}$, OD score distribution for animals raised under SCs (181 cells) and those treated with DMSO (147 cells) did not significantly differ between each other (Kolmogorov-Smirnov test, $p=0.540$ ), whereas OD distribution for the SAHA-treated group (109 cells) was significantly shifted in favor of the deprived eye (Kolmogorov-Smirnov test, $p<0.01$ for both comparisons). C, D, The functional basic properties of visual cortical neurons were not affected in SAHA- and DMSO-treated animals. The data for cell responsiveness are represented as box charts. No statistical differences were present among all groups for either cell responsiveness ( $\boldsymbol{C}$, KruskalWallis one-way ANOVA on ranks, $p=0.939$ ) or RF size distribution (mean RF size: $\mathrm{SC}=16.6^{\circ} \pm 1.1^{\circ}$; $\mathrm{SAHA}=18.5^{\circ} \pm 1.6^{\circ}$; DMSO $=19.0^{\circ} \pm 0.9^{\circ}$; one-way ANOVA, $p=0.289$ ). The asterisk indicates statistical significance: ${ }^{*} p<0.05$. Data are expressed as the mean \pm SEM.

lase inhibitor SAHA increased $\mathrm{H} 3$ acetylation in rats raised under SCs and was sufficient to determine a faster closure of the CP in the same group. These results are in agreement with previous findings obtained in the mouse, which showed that exposure to early EE results in an earlier binocular matching of orientation preference, likely mediated by increased histone acetylation in the visual cortex (Wang et al., 2013). As suggested by Wang et al. (2013), a precocious plastic window might negatively affect visual function development when the earlier time course for plasticity is not matched by an earlier maturation of visual functions. Here we showed that the accelerated time course for OD plasticity induced by EE did not result in any detrimental effect for visual function maturation, as indicated by similar visual depth perception abilities in animals raised with EE and under SCs at the CP end and by our previous data concerning visual acuity maturation (Landi et al., 2007).

We also showed that EE induced a pronounced increase in $\mathrm{H} 3$ acetylation in the developing hippocampus, demonstrating that EE effects were not confined to the visual cortex.

Our results also suggest that histone acetylation changes might act as the link between sensory experience and the activity modulation of genes involved in brain plasticity, like BDNF. BDNF exerts a profound influence on visual system development. Mice overexpressing BDNF exhibit a pronounced acceleration in both the development of visual acuity and the time course of OD plasticity (Huang et al., 1999), and we have previously provided evidence that, regarding visual acuity maturation, changes very similar to these can also be induced by early exposure to $\mathrm{EE}$, which is associated with early increases in V1 BDNF protein levels (Sale et al., 2009). Now, we further explored the capability of EE to impact on developmental plasticity in the primary visual cortex, showing that EE also leads to an earlier closure of the CP for the effects of $\mathrm{MD}$ and an upregulation of histone H3 acetylation at the level of the P3 BDNF gene promoter. The increased acetylation at P3 was paralleled by an increased relative amount of $\mathrm{P} 3 \mathrm{BDNF}$ mRNA relative to total BDNF mRNA, suggesting a positive effect of histone acetylation on activity-dependent BDNF gene expression. While the regulation of BDNF promoter acetylation in the cerebral cortex has been investigated in response to various pharmacological treatments or, in exercised animals, in the hippocampus (Fuchikami et al., 2010; Tian et al., 2010; Zeng et al., 2011; Intlekofer et al., 2013), to our knowledge, this is the first time that a specific epigenetic control at the BDNF gene promoter is reported as a likely underlying mechanism for visual cortical plasticity during the CP.

One of the possible contributing factors for the early effects induced by EE might be maternal care, one major regulator for the programming of individual differences. Weaver et al. (2004) have shown that offspring differences in stress response depend on epigenetic changes in the promoter of the glucocorticoid receptor gene, under the direct control of maternal care levels received by pups during the first postnatal week. Moreover, we previously reported (Sale et al., 2004) that enriched pups receive higher levels of maternal and nonmaternal licking and grooming. The EE-dependent acceleration of visual acuity maturation is mimicked in rat pups raised under SCs by a cycle of artificial massages reproducing sustained maternal behavior (Guzzetta et al., 2009). Thus, higher maternal care levels received by enriched pups might also have an effect on $\mathrm{H} 3$ acetylation levels, even if a direct influence of enriched stimuli on the developing subject is not negligible, once pups start exploring the surrounding area after eye opening.

Finally, we focused on adult rats, showing that 2 weeks of EE is a sufficient length of time to induce an increase of histone acetylation in the visual cortex. This finding suggests that EE drives a transitory epigenetic remodeling of chromatin structure that underlies the reinstatement of juvenile-like plasticity in the visual system, with possible implications for the treatment of visual 
deficits, like amblyopia. It has been shown that an increase in histone acetylation might be used to promote functional recovery in adult amblyopic rats (Silingardi et al., 2010), but how to translate these invasive treatments in manipulations useful for amblyopic humans remained unclear. Our results suggest that an increment in sensory-motor stimulation might be used to impact on the chromatin functional state, promoting plasticity in the adult visual cortex (Sale et al., 2007).

Our results, together with those previously reported concerning GABAergic inhibition levels in enriched animals, show that the same perturbation (EE) is associated with an increase of histone acetylation and BDNF in the visual cortex, with opposite effects occurring in the juvenile or adult brain [i.e., respectively increased inhibition paralleled by earlier closure of the plasticity window (Bartoletti et al., 2004; Cancedda et al., 2004; Landi et al., 2007) or reduced inhibition accompanied by OD plasticity reinstatement (Baroncelli et al., 2010, 2011, 2012; Mainardi et al., 2010; Scali et al., 2012; Tognini et al., 2012; Greifzu et al., 2014)]. In the developing visual system, it has been well documented that BDNF directly promotes the maturation of GABAergic neurotransmission both at the presynaptic and postsynaptic level, leading to the stabilization of inhibitory synapses (Huang et al., 1999; Gianfranceschi et al., 2003; Abidin et al., 2008). Thus, the early increase in BDNF detected in developing pups reared from birth in an enriched environment (Cancedda et al., 2004; Sale et al., 2004) might be the prime trigger factor guiding the development of inhibitory circuitry in the immature brain, when GABAergic interneurons are particularly sensitive to the trophic action of this neurotrophin. In the adult visual system, once the mature level of GABAergic inhibition has been reached and the critical period is closed in the primary visual cortex, the increase in BDNF prompted by a histone acetylation enhancement might lead to a suppression of GABAergic inhibition, as reported for other brain regions (Tanaka et al., 1997; Frerking et al., 1998; Henneberger et al., 2002), with BDNF inducing a reduction in postsynaptic $\mathrm{GABA}_{\mathrm{A}}$ receptor numbers that is responsible for the decline in GABAergic mIPSC amplitudes (Brünig et al., 2001). The direction of BDNF effects on inhibitory synapses could depend both on the preferred postsynaptic signaling cascade activated by the TrkB receptor (Mizoguchi et al., 2003) and the phosphorylation state of the GABA receptors (Jovanovic et al., 2004), and has been previously reported to be dependent of age, which is in agreement with our model (Mizoguchi et al., 2003).

It is also worth noting that visual cortex infusion of BDNF antisense oligonucleotides only partially blocks the OD shift in response to $\mathrm{MD}$ in adult animals in which the $\mathrm{CP}$ has been reopened by exposure to EE (Baroncelli et al., 2010). This
B

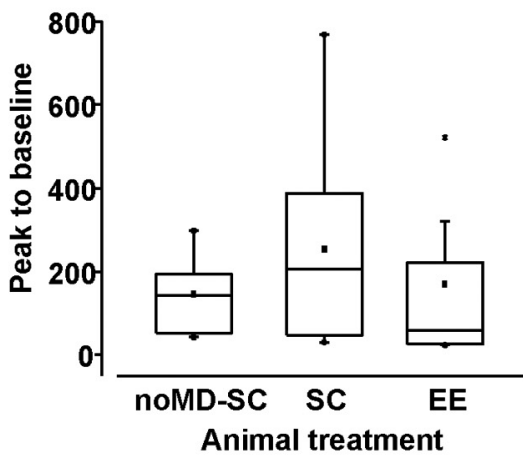

D
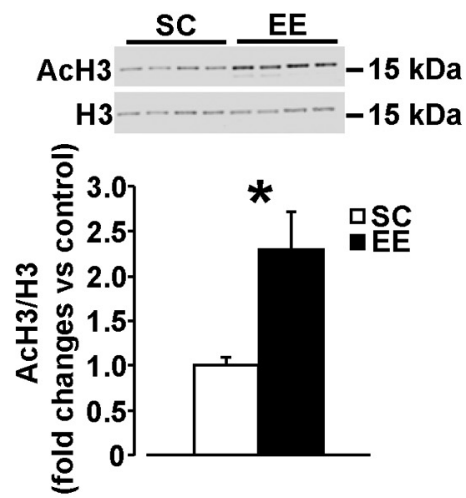

Figure 8. Environmental enrichment restores $\mathrm{OD}$ plasticity in adulthood and increases $\mathrm{H} 3$ acetylation in the visual cortex of adult animals. $A$, Filled symbols represent the average $C B I \pm S E M$ for each experimental group; open symbols represent the $C B I$ of al recorded. After $7 \mathrm{~d}$ of MD, the CBI of SC rats was completely comparable to that of noMD-SC animals (SC rats: $n=$ $7, \mathrm{CBI}=0.59 \pm 0.04 ; \mathrm{noMD}-\mathrm{SC}: n=5, \mathrm{CBI}=0.64 \pm 0.04$; one-way ANOVA, post hoc Holm-Sidak method, $p=0.342$ ), whereas (B) noMD-SC (132 cells), SC (189 cells), and EE animals (211 cells: Kruskal-Wallis one-way ANOVA on ranks, $p=0.749$ ). Data are animals reared with $\mathrm{EE}$ for $14 \mathrm{~d}$ ). In each gel, the $\mathrm{ACH} 3 / \mathrm{H} 3$ ratio measured for all samples was normalized to the mean ratio calculated for the control group (SCS). Quantification of acetylated $\mathrm{H} 3$ levels revealed that EE conditions significantly increased histone acetylation in the adult visual cortex (SCS: $n=8 ; \mathrm{EE}: n=7 ; t$ test, $p<0.05$ ). Data are expressed as the mean \pm SEM. The asterisks denote significant differences: ${ }^{*} p<0.05 ;{ }^{* *} p<0.01$.

suggests that BDNF is one player, but not the only one, in the restoration of adult plasticity, likely acting in parallel with other molecular factors. The reduction of intracortical inhibition in adult enriched animals, indeed, might be prompted also by increased serotonin levels (Baroncelli et al., 2010; Niell and Stryker, 2010) or enhanced IGF-1 signaling (MayaVetencourt et al., 2012).

Outside the visual system, it has been shown that EE is able to rescue memory abilities in a mouse model of brain degeneration, acting through the enhancement of histone acetylation (Fischer et al., 2007). Our results extend this view to include the visual cortex, suggesting that optimization of external inputs elicits neural plasticity in the whole brain, leading to functional recovery in a number of different neural dysfunctions. Alone or in combination with suitable pharmacological treatments, exposure to procedures akin to EE might thus emerge as a fundamental route toward endogenous pharmacotherapy (Sale et al., 2014), a process by which brain circuits, appropriately fed with enhanced sensory inputs, are led to repair by unfolding their residual potential for plasticity. 


\section{References}

Abidin I, Eysel UT, Lessmann V, Mittmann T (2008) Impaired GABAergic inhibition in the visual cortex of brain-derived neurotrophic factor heterozygous knockout mice. J Physiol 586:1885-1901. CrossRef Medline

Baroncelli L, Sale A, Viegi A, Maya Vetencourt JF, De Pasquale R, Baldini S, Maffei L (2010) Experience-dependent reactivation of ocular dominance plasticity in the adult visual cortex. Exp Neurol 226:100-109. CrossRef Medline

Baroncelli L, Braschi C, Spolidoro M, Begenisic T, Maffei L, Sale A (2011) Brain plasticity and disease: a matter of inhibition. Neural Plast 2011: 286073. CrossRef Medline

Baroncelli L, Bonaccorsi J, Milanese M, Bonifacino T, Giribaldi F, Manno I, Cenni MC, Berardi N, Bonanno G, Maffei L, Sale A (2012) Enriched experience and recovery from amblyopia in adult rats: impact of motor, social and sensory components. Neuropharmacology 62:2388-2397. CrossRef Medline

Baroncelli L, Braschi C, Maffei L (2013) Visual depth perception in normal and deprived rats: effects of environmental enrichment. Neuroscience 236:313-319. CrossRef Medline

Bartoletti A, Medini P, Berardi N, Maffei L (2004) Environmental enrichment prevents effects of dark-rearing in the rat visual cortex. Nat Neurosci 7:215-216. CrossRef Medline

Bavelier D, Levi DM, Li RW, Dan Y, Hensch TK (2010) Removing brakes on adult brain plasticity: from molecular to behavioral interventions. J Neurosci 30:14964-14971. CrossRef Medline

Berardi N, Pizzorusso T, Maffei L (2000) Critical periods during sensory development. Curr Opin Neurobiol 10:138-145. CrossRef Medline

Blakemore C, Garey LJ, Vital-Durand F (1978) The physiological effects of monocular deprivation and their reversal in the monkey's visual cortex. J Physiol 283:223-262. CrossRef Medline

Brünig I, Penschuck S, Berninger B, Benson J, Fritschy JM (2001) BDNF reduces miniature inhibitory postsynaptic currents by rapid downregulation of $\operatorname{GABA}(\mathrm{A})$ receptor surface expression. Eur J Neurosci 13: 1320-1328. CrossRef Medline

Cancedda L, Putignano E, Sale A, Viegi A, Berardi N, Maffei L (2004) Acceleration of visual system development by environmental enrichment. J Neurosci 24:4840-4848. CrossRef Medline

Cynader M, Berman N, Hein A (1976) Recovery of function in cat visual cortex following prolonged deprivation. Exp Brain Res 25:139-156. Medline

Dews PB, Wiesel TN (1970) Consequences of monocular deprivation on visual behaviour in kittens. J Physiol 206:437-455. CrossRef Medline

Fagiolini M, Hensch TK (2000) Inhibitory threshold for critical-period activation in primary visual cortex. Nature 404:183-186. CrossRef Medline

Fagiolini M, Pizzorusso T, Berardi N, Domenici L, Maffei L (1994) Functional postnatal development of the rat primary visual cortex and the role of visual experience: dark rearing and monocular deprivation. Vision Res 34:709-720. CrossRef Medline

Fischer A, Sananbenesi F, Wang X, Dobbin M, Tsai LH (2007) Recovery of learning and memory is associated with chromatin remodelling. Nature 447:178-182. CrossRef Medline

Frerking M, Malenka RC, Nicoll RA (1998) Brain-derived neurotrophic factor (BDNF) modulates inhibitory, but not excitatory, transmission in the CA1 region of the hippocampus. J Neurophysiol 80:3383-3386. Medline

Fuchikami M, Yamamoto S, Morinobu S, Takei S, Yamawaki S (2010) Epigenetic regulation of BDNF gene in response to stress. Psychiatry Investig 7:251-256. CrossRef Medline

Gianfranceschi L, Siciliano R, Walls J, Morales B, Kirkwood A, Huang ZJ, Tonegawa S, Maffei L (2003) Visual cortex is rescued from the effects of dark rearing by overexpression of BDNF. Proc Natl Acad Sci U S A 100: 12486-12491. CrossRef Medline

Giffin F, Mitchell DE (1978) The rate of recovery of vision after early monocular deprivation in kittens. J Physiol 274:511-537. CrossRef Medline

Gordon JA, Stryker MP (1996) Experience-dependent plasticity of binocular responses in the primary visual cortex of the mouse. J Neurosci 16 : 3274-3286. Medline

Greifzu F, Pielecka-Fortuna J, Kalogeraki E, Krempler K, Favaro PD, Schlüter OM, Löwel S (2014) Environmental enrichment extends ocular dominance plasticity into adulthood and protects from stroke-induced impairments of plasticity. Proc Natl Acad Sci U S A 111:1150-1155. CrossRef Medline

Guan JS, Haggarty SJ, Giacometti E, Dannenberg JH, Joseph N, Gao J, Nie- land TJ, Zhou Y, Wang X, Mazitschek R, Bradner JE, DePinho RA, Jaenisch R, Tsai LH (2009) HDAC2 negatively regulates memory formation and synaptic plasticity. Nature 459:55-60. CrossRef Medline

Guzzetta A, Baldini S, Bancale A, Baroncelli L, Ciucci F, Ghirri P, Putignano E, Sale A, Viegi A, Berardi N, Boldrini A, Cioni G, Maffei L (2009) Massage accelerates brain development and the maturation of visual function. J Neurosci 29:6042-6051. CrossRef Medline

Henneberger C, Jüttner R, Rothe T, Grantyn R (2002) Postsynaptic action of BDNF on GABAergic synaptic transmission in the superficial layers of the mouse superior colliculus. J Neurophysiol 88:595-603. Medline

Huang ZJ, Kirkwood A, Pizzorusso T, Porciatti V, Morales B, Bear MF, Maffei L, Tonegawa S (1999) BDNF regulates the maturation of inhibition and the critical period of plasticity in mouse visual cortex. Cell 98:739-755. CrossRef Medline

Hubel DH, Wiesel TN (1970a) The period of susceptibility to the physiological effects of unilateral eye closure in kittens. J Physiol 206:419-436. CrossRef Medline

Hubel DH, Wiesel TN (1970b) Stereoscopic vision in macaque monkey. Cells sensitive to binocular depth in area 18 of the macaque monkey cortex. Nature 225:41-42. CrossRef Medline

Intlekofer KA, Berchtold NC, Malvaez M, Carlos AJ, McQuown SC, Cunningham MJ, Wood MA, Cotman CW (2013) Exercise and sodium butyrate transform a subthreshold learning event into long-term memory via a brain-derived neurotrophic factor-dependent mechanism. Neuropsychopharmacology 38:2027-2034. CrossRef Medline

Jovanovic JN, Thomas P, Kittler JT, Smart TG, Moss SJ (2004) Brainderived neurotrophic factor modulates fast synaptic inhibition by regulating $\mathrm{GABA}_{\mathrm{A}}$ receptor phosphorylation, activity, and cell-surface stability. J Neurosci 24:522-530. CrossRef Medline

Kilgore M, Miller CA, Fass DM, Hennig KM, Haggarty SJ, Sweatt JD, Rumbaugh G (2010) Inhibitors of class 1 histone deacetylases reverse contextual memory deficits in a mouse model of Alzheimer's disease. Neuropsychopharmacology 35:870-880. CrossRef Medline

Landi S, Sale A, Berardi N, Viegi A, Maffei L, Cenni MC (2007) Retinal functional development is sensitive to environmental enrichment: a role for BDNF. FASEB J 21:130-139. CrossRef Medline

Mainardi M, Landi S, Gianfranceschi L, Baldini S, De Pasquale R, Berardi N, Maffei L, Caleo M (2010) Environmental enrichment potentiates thalamocortical transmission and plasticity in the adult rat visual cortex. J Neurosci Res 88:3048-3059. CrossRef Medline

Maya-Vetencourt JF, Pizzorusso T (2013) Molecular mechanisms at the basis of plasticity in the developing visual cortex: epigenetic processes and gene programs. J Exp Neurosci 7:75-83. CrossRef Medline

Maya-Vetencourt JF, Baroncelli L, Viegi A, Tiraboschi E, Castren E, Cattaneo A, Maffei L (2012) IGF-1 restores visual cortex plasticity in adult life by reducing local GABA levels. Neural Plast 2012:250421. CrossRef Medline

Metsis M, Timmusk T, Arenas E, Persson H (1993) Differential usage of multiple brain-derived neurotrophic factor promoters in the rat brain following neuronal activation. Proc Natl Acad Sci U S A 90:8802-8806. CrossRef Medline

Mizoguchi Y, Ishibashi H, Nabekura J (2003) The action of BDNF on GABA(A) currents changes from potentiating to suppressing during maturation of rat hippocampal CAl pyramidal neurons. J Physiol 548: 703-709. CrossRef Medline

Mower GD (1991) The effect of dark rearing on the time course of the critical period in cat visual cortex. Brain Res Dev Brain Res 58:151-158. CrossRef Medline

Nabel EM, Morishita H (2013) Regulating critical period plasticity: insight from the visual system to fear circuitry for therapeutic interventions. Front Psychiatry 4:146. CrossRef Medline

Niell CM, Stryker MP (2010) Modulation of visual responses by behavioral state in mouse visual cortex. Neuron 65:472-479. CrossRef Medline

Prusky GT, Reidel C, Douglas RM (2000) Environmental enrichment from birth enhances visual acuity but not place learning in mice. Behav Brain Res 114:11-15. CrossRef Medline

Putignano E, Lonetti G, Cancedda L, Ratto G, Costa M, Maffei L, Pizzorusso T (2007) Developmental downregulation of histone posttranslational modifications regulates visual cortical plasticity. Neuron 53:747-759. CrossRef Medline

Sale A, Putignano E, Cancedda L, Landi S, Cirulli F, Berardi N, Maffei L (2004) Enriched environment and acceleration of visual system development. Neuropharmacology 47:649-660. CrossRef Medline 
Sale A, Maya Vetencourt JF, Medini P, Cenni MC, Baroncelli L, De Pasquale R, Maffei L (2007) Environmental enrichment in adulthood promotes amblyopia recovery through a reduction of intracortical inhibition. Nat Neurosci 10:679-681. CrossRef Medline

Sale A, Berardi N, Maffei L (2009) Enrich the environment to empower the brain. Trends Neurosci 32:233-239. CrossRef Medline

Sale A, Berardi N, Maffei L (2014) Environment and brain plasticity: towards an endogenous pharmacotherapy. Physiol Rev 94:189-234. CrossRef Medline

Scali M, Baroncelli L, Cenni MC, Sale A, Maffei L (2012) A rich environmental experience reactivates visual cortex plasticity in aged rats. Exp Gerontol 47:337-341. CrossRef Medline

Silingardi D, Scali M, Belluomini G, Pizzorusso T (2010) Epigenetic treatments of adult rats promote recovery from visual acuity deficits induced by long-term monocular deprivation. Eur J Neurosci 31:2185-2192. CrossRef Medline

Tanaka T, Saito H, Matsuki N (1997) Inhibition of GABA A synaptic responses by brain-derived neurotrophic factor (BDNF) in rat hippocampus. J Neurosci 17:2959-2966. Medline

Tian F, Marini AM, Lipsky RH (2010) Effects of histone deacetylase inhibitor Trichostatin A on epigenetic changes and transcriptional activation of
Bdnf promoter 1 by rat hippocampal neurons. Ann N Y Acad Sci 1199: 186-193. CrossRef Medline

Tognini P, Putignano E, Coatti A, Pizzorusso T (2011) Experiencedependent expression of miR-132 regulates ocular dominance plasticity. Nat Neurosci 14:1237-1239. CrossRef Medline

Tognini P, Manno I, Bonaccorsi J, Cenni MC, Sale A, Maffei L (2012) Environmental enrichment promotes plasticity and visual acuity recovery in adult monocular amblyopic rats. PLoS One 7:e34815. CrossRef Medline

Wang BS, Feng L, Liu M, Liu X, Cang J (2013) Environmental enrichment rescues binocular matching of orientation preference in mice that have a precocious critical period. Neuron 80:198-209. CrossRef Medline

Weaver IC, Cervoni N, Champagne FA, D’Alessio AC, Sharma S, Seckl JR, Dymov S, Szyf M, Meaney MJ (2004) Epigenetic programming by maternal behavior. Nat Neurosci 7:847-854. CrossRef Medline

Wiesel TN, Hubel DH (1963) Effects of visual deprivation on morphology and physiology of cells in the cats lateral geniculate body. J Neurophysiol 26:978-993. Medline

Zeng Y, Tan M, Kohyama J, Sneddon M, Watson JB, Sun YE, Xie CW (2011) Epigenetic enhancement of BDNF signaling rescues synaptic plasticity in aging. J Neurosci 31:17800-17810. CrossRef Medline 